$11^{\text {th }}$ ICEEPSY 2020

The International Conference on Education and Educational Psychology

\title{
KNOWLEDGE ABOUT THE CHANGES IN PUBERTY AMONG PREPUBESCENT CHILDREN IN SELECTED COUNTRIES
}

\author{
Miluše Rašková (a), Dominika Provázková Stolinská (b)*, Michaela Bartošová (c) \\ *Corresponding author
}

(a) Department of primary and pre-primary education, Faculty of education, Palacký University Olomouc, Žižkovo nám 5, Olomouc, 771 40, Czech Republic

(b) Department of primary and pre-primary education, Faculty of education, Palacký University Olomouc, Žižkovo nám 5, Olomouc, 771 40, Czech Republic, dominika.stolinska@gmail.com

(c) Department of primary and pre-primary education, Faculty of education, Palacký University Olomouc, Žižkovo nám 5, Olomouc, 771 40, Czech Republic

\begin{abstract}
Puberty is an important element of sex education in the global dimension. The pre-pubescent needs to be adequately prepared in time for puberty, for all changes, relationships and contexts. The cognitive and informative level of puberty knowledge represents the level of learning and expresses the amount and quality of information or knowledge. Our pedagogical research realized the level of knowledge about changes in puberty shown by primary school pupils the Czech Republic, Sweden, China, Spain. We used the didactic knowledge test to determine knowledge about changes in puberty among primary school pupils. The level of knowledge about changes in puberty was verified by selected test tasks. We used descriptive statistics to describe the data. The non-parametric Kruskal-Wallis test was used to identify statistically significant differences in pupil responses across countries. The results pointed out that the pre-pubescent people did not have the right knowledge and did not comprehend the relationships and connections with the issue of puberty comprehensively. The prepubescent often do not realize the biological aspect and its importance for the future reproductive life of each person in the context of further changes. Puberty can be described as a fundamental hormonal process of physical changes. Early adolescence preparedness means that children should acquire the necessary knowledge about it before it starts, even when they are primary school pupils. Educational research conducted by us investigated the level of knowledge about changes in puberty shown by primary school pupils in selected countries.
\end{abstract}

2672-8141 (C) 2020 Published by European Publisher.

Keywords: Pre-puberty, puberty, pupils, knowledge, testing. 


\section{Introduction}

The present research focuses on the identification of the cognitive and informative level of knowledge about puberty among primary school pupils (by means of testing) and information about mutual communication about puberty among primary school pupils, their teachers, and families (by means of a survey among pupils). The key concepts of the present research are puberty and knowledge about puberty among primary school pupils. The paper focuses on the level of knowledge about the changes in puberty, as reported by primary school pupils in selected countries.

The empirical research started in 2015 in the Czech Republic and later included other countries (China in 2016, Spain in 2018, Sweden in 2019, Croatia in 2020). The research is part of a student grant competition at Palacký University Olomouc (IGA_PdF_2020_023; Cognitive and informative level of knowledge about puberty among primary school pupils in Croatia; principal investigator Doc. PaedDr. Miluše Rašková, Ph.D.). Given the situation with the spreading of COVID-19 coronavirus in Europe and closure of schools in spring this year, so far the authors have been unable to statistically evaluate the data in the context of other countries because data collection in elementary schools in Croatia was conducted at a later date. For this reason, the comprehensive results from Croatia are not included in the paper as they are currently being processed.

\section{Problem Statement}

The focus of the research problem is on identifying the level of knowledge about puberty among primary school children before its onset. Prepubescent children need to be prepared for puberty in time and in an appropriate manner; this should include all related associations and contexts. Timely readiness for puberty means that children have the required knowledge before its onset when they are in primary school. Knowledge is gained in the process of learning and represents the level of awareness. The cognitive and informative level of knowledge about puberty includes the amount and quality of relevant information.

Most information is of a general nature and forms an integral part of general knowledge. The system of acquired knowledge and skills is a part of education and forms a holistic human personality. The personality of an educated person should match the culture of the era. Education also includes the adoption of values and the development of the attitude towards the world, society, and oneself. The attitudes are reflected in the ability of critical thinking and in the opinions and behaviour in practical life.

\section{Research Questions}

In relation to the research problem, the researchers focused on the area that represents the level of knowledge about the changes in puberty among pubescent children. The part of the educational research study performed by the researchers focused on the level of knowledge about the changes in puberty among primary school children in selected countries (Czech Republic, Sweden, China, Spain, and newly Croatia-see introduction). 


\section{Purpose of the Study}

The purpose of the study was to show whether prepubescent children were sufficiently educated in the area of the changes in puberty. The researchers also focused on whether prepubescent children understood puberty comprehensively with respect to all changes in the biological, psychological, and social areas, taking into account the specificity of both genders.

In the life of every person, puberty is an important part of human development. During puberty, the signals that concern the hormonal changes that are required are sent from the brain to the reproductive organs, which stimulate growth, development of functions, and other changes in the brain and other organs. Along with the hormonal process of physical changes in both genders, during which the reproductive organs mature and start to produce sex hormones (sperms or ova), changes are taking place in the physical structure. During that period, growth is decelerated or even stopped, while changes in the physical structure and the appearance of secondary sex characteristics, including pubic hair in the armpit, skin changes, and acne development also take place. Changes in boys further include body thickening and muscle growth, pubic hair on the scrotum, hair on the face, and voice change. Changes in girls include hair in the pubic area, gaining female shape of the body, and breast growth.

The period of puberty is marked also by significant psychological changes including becoming aware of others' personality. Puberty is a period of searching for and building one's identity. The manifestations of psychological changes in puberty include refusal of a subordinate role that changes the individual's social role and causes attacks against authorities including the parents and teachers. Changes take place in the attitude towards the school and the teachers as well, which are no longer considered a formal authority, unless there is something to be impressed by. Generally, adolescent children want to participate in decision making about matters related to them and they start to critically assess their parents and other adults. Leisure time is a significant aspect in the life of an adolescent. They want to spend time with their friends. For some individuals, puberty may become an impulse for artistic expression, reading complex literary works, doing attractive sports, interest in mysteriousness, romance, nature, and other activities. Pubescents tend to be emotionally instable. There are changes in their self-evaluation, they tend to be touchy and vulnerable. According to psychologists, the reason behind this emotional instability is primarily the hormonal changes. Secondarily, instability may be supported by psychological changes and changes in interpersonal relationships. In puberty, there are also changes in the way of thinking. During that period, individuals start to think hypothetically (at the level of formal logical operations), a process that affects not only their overall attitude to the world but also to themselves.

\section{Research Methods}

The data collection was performed by means of non-standardized knowledge achievement tests (see Example). The level of knowledge about puberty was tested by means of nine items with open-ended answers. The content of the test items focused on the definition of puberty (Q1); puberty age range in both genders (Q2 to Q5); knowledge about physical changes in boys and girls (Q6 to Q7); knowledge about other changes that puberty induces in both genders (Q8); significance of puberty in human life (Q9). The pupils' responses in the test were coded by means of the following numbers: $2=$ correct answer, $1=$ partially correct answer, $0=$ incorrect answer. Test items with a missing answer were coded 
with the number 5 . The data were described by means of descriptive statistics. To identify any statistically significant differences in the pupils' responses by countries, the non-parametric Kruskal-Wallis test was used.

The present paper focuses on the level of knowledge about the changes in puberty between prepubescent children. For this reason, the results of test items Q6-Q8 were used.

\section{Example of the questionnaire:}

PUBERTY

Dear children, please answer the questions about puberty. Do not sign the form!
I am a (circle):
a) boy
b) girl

I am years old.

A) WHAT DO YOU KNOW ABOUT PUBERTY?

1. Puberty is

2. For boys, puberty begins approximately at the age of:

3. For girls, puberty begins approximately at the age of:

4. For boys, puberty ends approximately at the age of:

5. For girls, puberty ends approximately at the age of:

6. Specify the changes in physical characteristics during puberty in boys:

7. Specify the changes in physical characteristics during puberty in girls:

8. Specify other changes during puberty in boys and girls: 


\section{Findings}

The research sample included a total of 349 prepubescent children from the Czech Republic, China, Spain, and Sweden aged 10 to 12 years. The comparison of the overall results using the KruskalWallis test showed that the overall score achieved by the boys and girls in the test significantly differed in the countries involved ( $<<0.0001$, see Table 1 below). Significant differences were also observed in the comparison of the overall point score of the responses between all countries $(\mathrm{p}<0.05$-significant differences between the results of the boys and girls from the countries involved).

Table 01. Kruskal-Wallis test - comparison of the overall test results

\begin{tabular}{|l|l|l|l|l|}
\hline \multirow{4}{*}{} & \multicolumn{4}{|l|}{$\begin{array}{l}\text { Multiple Comparisons p value (2-tailed); Score (DATA) } \\
\text { Independent (grouping) variable: CONTRY } \\
\text { Kruskal-Wallis test: H (3, N=349) }=\mathbf{7 4 , 6 4 6 6 7} \mathbf{~}=, \mathbf{0 0 0 0}\end{array}$} \\
\cline { 2 - 5 } $\begin{array}{l}\text { Depend.: } \\
\text { Score }\end{array}$ & $\begin{array}{l}\text { Czech } \\
\text { R: } \mathbf{1 7 3 , 4 0}\end{array}$ & $\begin{array}{l}\text { China }: \mathbf{1 3 6 , 4 0} \\
\text { Rpain } \\
\text { R: } \mathbf{3 0 7 , 7 7}\end{array}$ & $\begin{array}{l}\text { Sweden } \\
\text { R: 222,43 }\end{array}$ \\
\hline Czech & & 0,012794 & 0,000000 & 0,033091 \\
\hline Spain & 0,012794 & & 0,000000 & 0,000008 \\
\hline Sweden & 0,000000 & 0,000000 & & 0,004199 \\
\hline
\end{tabular}

The following text describes the overall results concerning the level of knowledge about the changes in puberty in the countries involved with a focus on physical changes in boys (Q6) (Figure 01) and girls (Q7) (Figure 02) and other changes that puberty induces in both genders (Q8) (Figure 03).

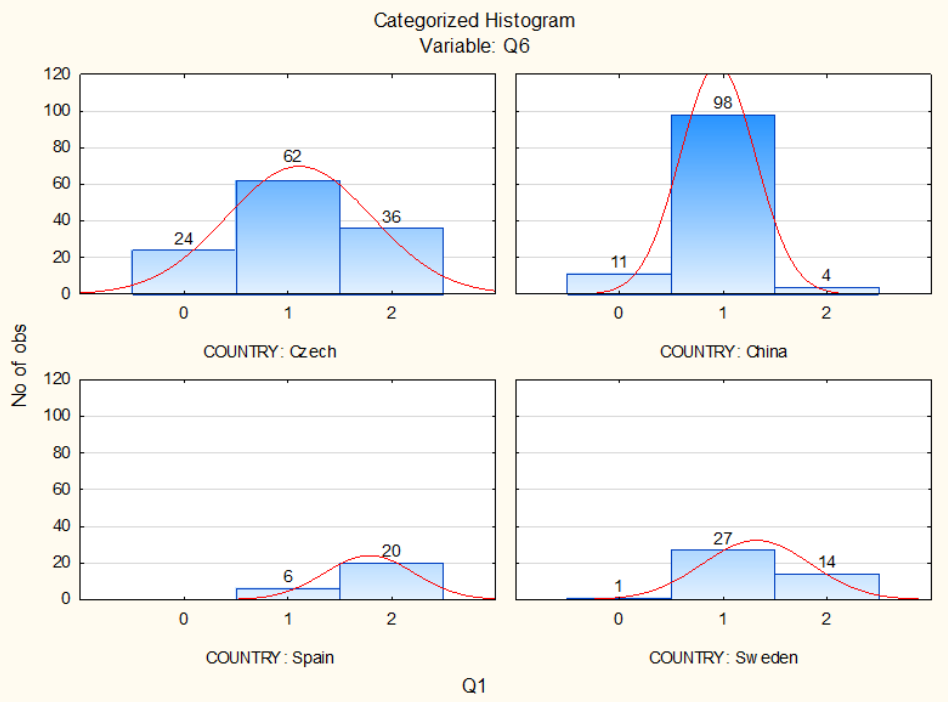

Figure 01. Comparison of the achieved point score in question 6 by countries-physical changes in puberty in boys)

Note: correct answer (2), partially correct answer (1), incorrect answer (0) 


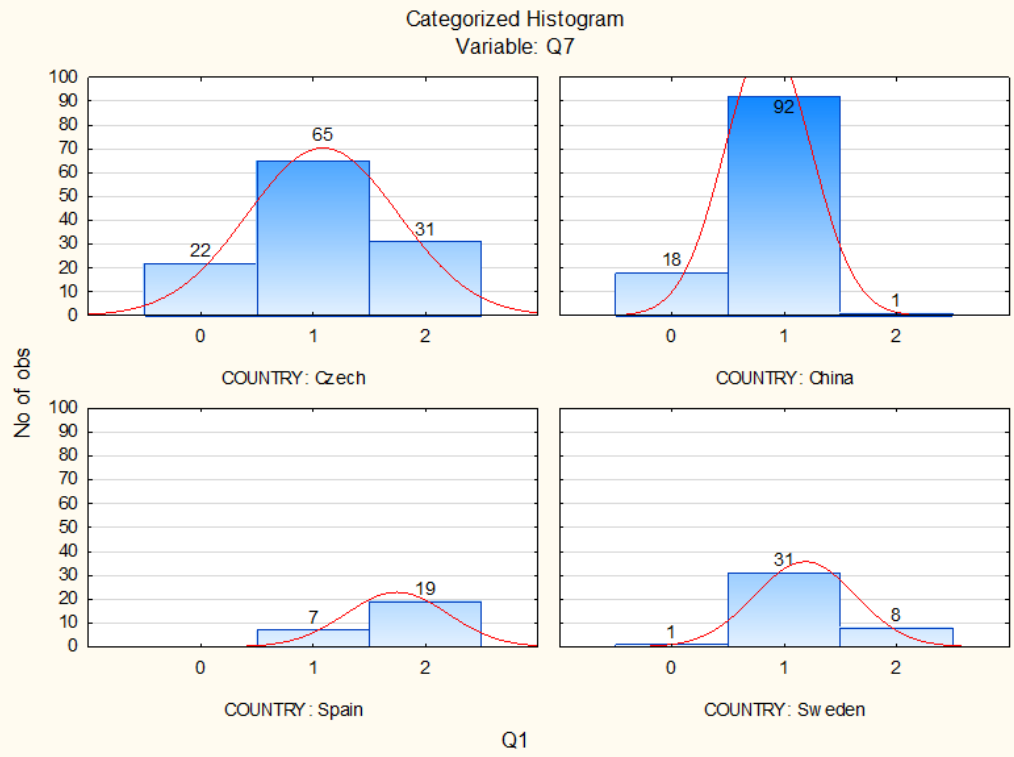

Figure 02. Comparison of the achieved point score in question 7 by countries—physical changes in puberty in girls

Note: correct answer (2), partially correct answer (1), incorrect answer (0)

Results (Q6, Q7): Most of the answers of the Swedish, Czech, and Chinese respondents were in the category of partially correct answers, which suggests basic awareness in the area of physical changes during the period of puberty in both genders. These respondents suggested only various incomplete combinations of changes, meaning that they do not have appropriate knowledge from a comprehensive perspective. The most frequent answers of the respondents from Spain confirmed their knowledge about the issue.

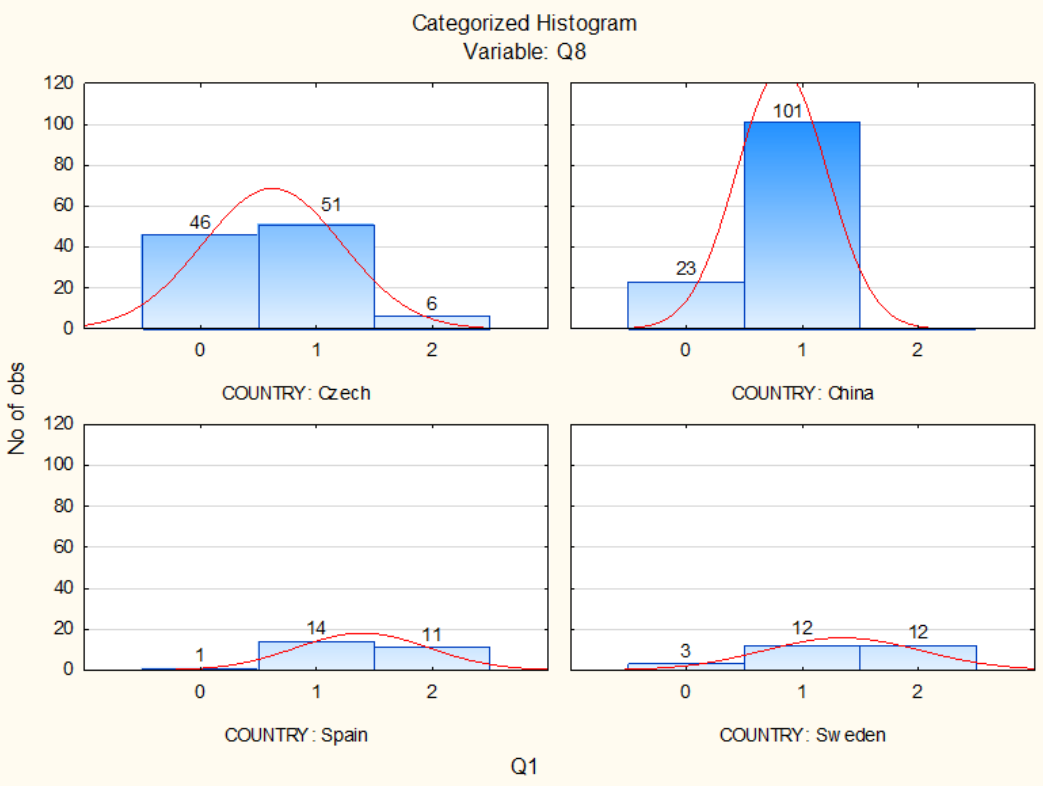

Figure 03. Comparison of the achieved point score in question 8 by countries — other changes in puberty in boys and girls

Note: correct answer (2), partially correct answer (1), incorrect answer (0) 
Results (Q8): The answers also suggest the respondents' awareness of other changes than biological. Most of the responses were in the category of partially correct answer. The respondents indicated only various incomplete combinations of other changes. The most frequent responses included the need to spend leisure time with peers, aspects associated with emotional instability, love and affection, and the need to participate in decision making on matters that relate to them. In this question, the least knowledge was shown by the respondents from the Czech Republic.

\section{Conclusion}

The incomplete or missing knowledge about puberty suggests that prepubescent children do not consider the issue of puberty and relevant associations and contexts in a comprehensive way. Younger school-aged prepubescent children are often unaware of the biological aspect and its importance for future reproductive life of each person in context with other changes. Prepubescent children usually associate puberty only with psychosocial changes.

These findings suggest that teachers should strengthen the knowledge of prepubescent children about puberty in a comprehensive manner including all changes in the biological, psychological, and social areas, taking into account the specificity of each gender.

The results concerning the level of knowledge about puberty among boys and girls in the countries involved (Q1-Q9) have been continuously published (Rašková \& Otavová, 2019; Rašková \& Provázková Stolinská, 2015a, 2015b, 2017, 2018; Rašková \& Vavrdová, 2019; Rašková et al., 2015 etc.). The aim of paper was to emphasise the insufficient or missing knowledge concerning the changes in puberty among prepubescent children across the countries involved.

The testing of the knowledge among prepubescent children in selected countries revealed their incomplete knowledge. It was observed that the respondents' knowledge was not completely absent, but rather that they did not understand puberty comprehensively. It was observed that they did not associate the achievement of the reproduction ability, full sexual maturity, and the completion of physical growth with psychological and social changes.

In the area of physical changes during puberty in both genders, the respondents reported in their answers various incomplete combinations of changes. Although the respondents were aware of other than biological changes, in their responses they indicated only various incomplete combinations of other changes (most frequent responses included the need to spend leisure time with peers, aspects associated with emotional instability, love and affection, and the need to participate in decision making on matters that relate to them).

These findings are especially important to teachers, who should focus their work on strengthening the development of comprehensive knowledge about puberty. Education should also include the knowledge about the changes in puberty. From an educational perspective, the complete knowledge about puberty is part of overall personality development.

\section{Acknowledgments}

The authors would like to thank their Chinese colleague Wan Zhang Wei for excellent cooperation in the implementation of the research in China. The authors would also like to thank their colleagues 
Isabel Morales Jareňo (University of Madrid) and Ellen Matlock Ziemann (University of Uppsala), who cooperated with our Spanish and Swedish partners, respectively.

Gratitude also goes to Prof. Robert Bacalja (University of Zadar) who has become our new partner in Croatia.

Finally, we would like to thank Miroslav Chráska Jr. for the statistical processing of the results. Our thanks also go to all the students who participated in the research.

\section{References}

Rašková, M., \& Provázková Stolinská, D. (2015a). Cognitive and informative level of knowledge about puberty of Czech elementary school students. SGEM.

Rašková, M., \& Provázková Stolinská, D. (2015b). Puberty as the concept of pedagogical theory and practice. IAC-TLEI.

Rašková, M., \& Provázková Stolinská, D. (2017). Teacher-Student Communication about Puberty in Elementary School. Ireland International Conference on Education. IICE.

Rašková, M., Provázková Stolinská, D., \& Vavrdová, A. (2015). Educational premises of puberty at primary school. ICLEL.

Rašková, M., \& Provázková Stolinská, D. (2018). Knowledge about Puberty among Primary School Children in the Czech Republic. In 11th annual International Conference of Education, Research and Innovation. Seville.

Rašková, M., \& Provázková Stolinská, D. (2018). Cognitive and informative level of knowledge about puberty among primary school pupils in the Czech Republic, China and Spain. In The International conference on Education and Educational Psychology. Athens.

Rašková, M., \& Provázková Stolinská, D. (2018). Cognitive and Informative Level of Knowledge about Puberty among Primary School Pupils in the Czech Republic and in China. In Educating for change - The European conference on education. Brighton.

Rašková, M., \& Otavová, M. (2019). Cognitive and Informative Level of Knowledge about Puberty in Primary School Pupils in Sweden. In The European Conference on Education 2019. Official Conference Proceedings. The International Academic Forum (IAFOR).

Rašková, M., \& Vavrdová, A. (2019). Comparison of puberty knowledge in primary school pupils in the Czech Republic, China, Spain and Sweden. In EDULEARN19 Proceedings (pp. 2695-2701). International Association of Technology, Education and Development (IATED). 